UNDERGRADUATE RESEARCH IN NATURAL AND CLINICAL SCIENCE AND TECHNOLOGY (URNCST) JOURNAL Read more URNCST Journal articles and submit your own today at: https://www.urncst.com

\title{
The Effects of Circadian Rhythm in Adolescents on Optimal Performance in Cognitive Tasks
}

\author{
Giulia Clarizio, BSc Student [1]*, Priyanka Gill, BSc [1] \\ [1] Department of Science, Western University, London, Ontario, Canada N6A 3K7 \\ *Corresponding Author: gclarizi@uwo.ca
}

\begin{abstract}
Introduction: The circadian rhythm is a sleep-wake cycle determined by differences in serum melatonin and cortisol levels, and affects cognition and behaviour. Past research suggests that young adults tend to perform better on cognitive tasks during the afternoon and evening, which may be the optimal time of day in this population. This research protocol seeks to determine whether cognitive performance is affected at times assumed to be optimal for both populations (evening) compared with suboptimal times (morning).

Methods: Individuals would be recruited and divided into two groups: adolescents 13-17 and younger adults aged ages 18-25, with all participants of the afternoon/evening chronotype. Saliva is collected directly preceding test-taking. Each group completes a standard computerized test of simple math, logical reasoning, and executive function at both their optimal time of day (TOD) (3:00 to 6:00 PM) and at their non-optimal time of day (8:00 to 11:00 AM). Neuroelectric activity is recorded using electroencephalography (EEG).

Results: We hypothesize that adolescents and younger adults will be at their optimal performance level (measured by EEG and behavioural measures) between 3 to 6 P.M. rather than from 8 to 11 AM, due to their circadian rhythm. We expect TOD to influence reaction times and accuracy during task completion. A difference will be seen across many neural indices such as event-related potentials (ERPs) and alpha and theta power demonstrating optimal performance in the evening.

Discussion: Higher cortisol levels and changes in amplitude and latency of P3, N2Pc, N450, and PD ERP indices and differences in alpha and theta frequencies may be associated with optimal cognitive performance. This is related to faster response time, focus, and overall higher accuracy. Based on the anticipated results, one could alter the timing of task completion to fit different age groups' peak mental ability.

Conclusion: Continuously working at non-optimal times could lead to chronic circadian rhythm disruption, which could result in the deterioration of physical and mental health. Aspects of everyday life, such as student test-taking times, can be improved to benefit both individuals and institutions by catering to an individual's optimal TOD.
\end{abstract}

Keywords: time of day; chronotype; circadian rhythm; adolescents; electroencephalography; event-related potentials; cognitive performance

\section{Introduction}

The circadian rhythm is the body's natural biological clock that affects physiology and behaviour [1]. This sleepwake cycle is primarily controlled by hormones such as melatonin, a hormone heavily influenced by darkness and light, and cortisol, a hormone produced in the adrenal cortex and is largely secreted in the morning compared to at night [1]. Interruptions in the hormone production cycle can result in mood changes, dizziness, and potentially lead to increased distractibility [1]. These adverse effects have encouraged research into how individuals are able to synchronize their circadian rhythms to external time signals such as school hours [2]. Behavioural performance is heavily dependent on their chronotype, one's disposition for activity at certain times in the day [3]. Research has suggested that older individuals are more likely to be mentally active in the morning than the night, compared to adolescents who are more mentally active in the afternoon and evening [2].

Studies have shown that changes that occur as one matures from an adolescent to an adult include the duration, quality, and timing of sleep [2]. One of the most prominent changes that occur regarding the biological timing as one ages is a sleep shift to earlier hours. This shift in sleep, combined with homeostatic processes, affect fatigue levels and alertness throughout the day. It has been suggested that times of optimal cognitive performance occur at certain times, but suboptimal performance at other times depending on one's sleep cycle [2]. 
UNDERGRADUATE RESEARCH IN NATURAL AND CLINICAL SCIENCE AND TECHNOLOGY (URNCST) JOURNAL Read more URNCST Journal articles and submit your own today at: https://www.urncst.com

Cognitive performance has been measured with electroencephalography (EEG) and may be optimal for examining these changes in optimal and suboptimal performance at various times of the day. EEG measurements are taken while various cognitive tasks are conducted. When combined with a cognitive task, EEG can measure event-related potentials (ERPs), which are neural correlates that can index a specific cognitive function. They are tiny voltages generated in brain regions in response to specific stimuli and are often used to study mental processes [3]. These wave forms can be described according to their peak latencies which is the time after stimulus onset at which the ERP displays its most prominent negative or positive amplitude [3]. Since these ERP measures are so sensitive, they can reveal changes in cognitive processing that may be masked by variability in behavioural performance. For example, the Stroop task is a widely known measure of selective attention and allocation of attentional resources and elicits the N450 and P3 [3]. The Simon task uses indices of attentional selection (N2pc) and suppression (PD), which indicate the inability to suppress visual distractions [3]. The n-back task has been used to examine working memory processing by looking at the P3 to detect differences in the working memory processingload [4]. Both the comparison and calculation arithmetic task can measure cognitive effort through the oscillatory power in theta and alpha frequencies [5]. The use of these tests can help determine the effects that the circadian rhythm has on cognitive function at various times of the day [6].

As seen in previous studies, a major shift in sleep patterns occurs as one ages past 50 due to the presence of external factors, such as occupational obligations [7]. These masking factors are also present in children and adolescents although the two groups differ in circadian rhythm trends. Research has focused primarily on adults engaged in shift work, such as nurses and firefighters, due to the high-stakes nature of these jobs and the prevalence of problems that occur during working hours [7]. However, similar issues of differing circadian rhythms are also likely prominent in adolescents and college/university-aged individuals. If circadian rhythms play a large role in overall cognitive development and learning, this may adversely affect their social-occupational functioning and academic achievement.

This study seeks to determine whether cognitive performance is affected at times assumed to be optimal for adolescents and younger adults. Since prior research has shown that these age groups perform optimally in the afternoon and evening, we expect to see cognitive performance enhanced in this optimal time compared to the morning. The present research protocol proposes Stroop and Simon tasks to measure distractibility, an n-back test to measure working memory, and numerical comparison and calculation tasks to measure mathematical competency.

\section{Methods}

Participants

Individuals would be recruited and divided into two groups: adolescents 13-17 and younger adults aged 18-25, with all participants of the afternoon/evening chronotype. Their chronotypes will be assessed through a demographic questionnaire providing information regarding age, gender, education, daily routines, and typical sleep-wake times. Baseline data, including hormone levels, would be collected from participants by performing an enzyme-linked immunosorbent assay using participants' saliva, which would be collected directly preceeding test-taking. This allows us to detect any abnormalities in cortisol and melatonin levels by using antibodies from the saliva that bind to a plate which is then washed [8]. Interactions between antigens and antibodies allow for the detection of the hormone of interest [8]. To then allow for proper statistical analysis of the sample the process is repeated multiple times [8]. Individuals that do not fall within the normal hormone levels for their age or sex would then be excluded from the study. Saliva is collected directly preceding test-taking.

\section{Procedure}

Each group completes a standard computerized test of simple math, working memory, and distractibility at both their hypothesized optimal TOD (3:00 to 6:00 PM) and at their non-optimal TOD (8:00 to 11:00 AM). During these tests, the participants' neuroelectric activity is recorded using EEG. A 64-electrode montage will be used (Figure 3a and $\underline{3 b}$ ). All participants will be seated in a classroom setting with 10 silent confederate volunteers to mimic a typical classroom and obtain the most realistic results reflecting their true cognitive ability in classroom environments. Each participant will then be seated at a computer equipped with headphones. Participants will be required to perform each task with three blocks per task, with each block containing 100 trials.

\section{$\underline{\text { Stroop Task }}$}

The Stroop Task assesses processing speed and selective attention. Participants will be shown a colour word in a font colour that may be different than the semantic content [9]. Participants will be instructed to determine the font colour without reading the word with a computer keyboard ( $\mathrm{D}=$ Red, $\mathrm{F}=\mathrm{Green}, \mathrm{J}=$ Yellow, $\mathrm{K}=\mathrm{Blue}$ ) as quickly and accurately as possible. Incongruent trials are where the font colour is different from the colour word; congruent trials are where the word and word colour are the same (Figure 1). 


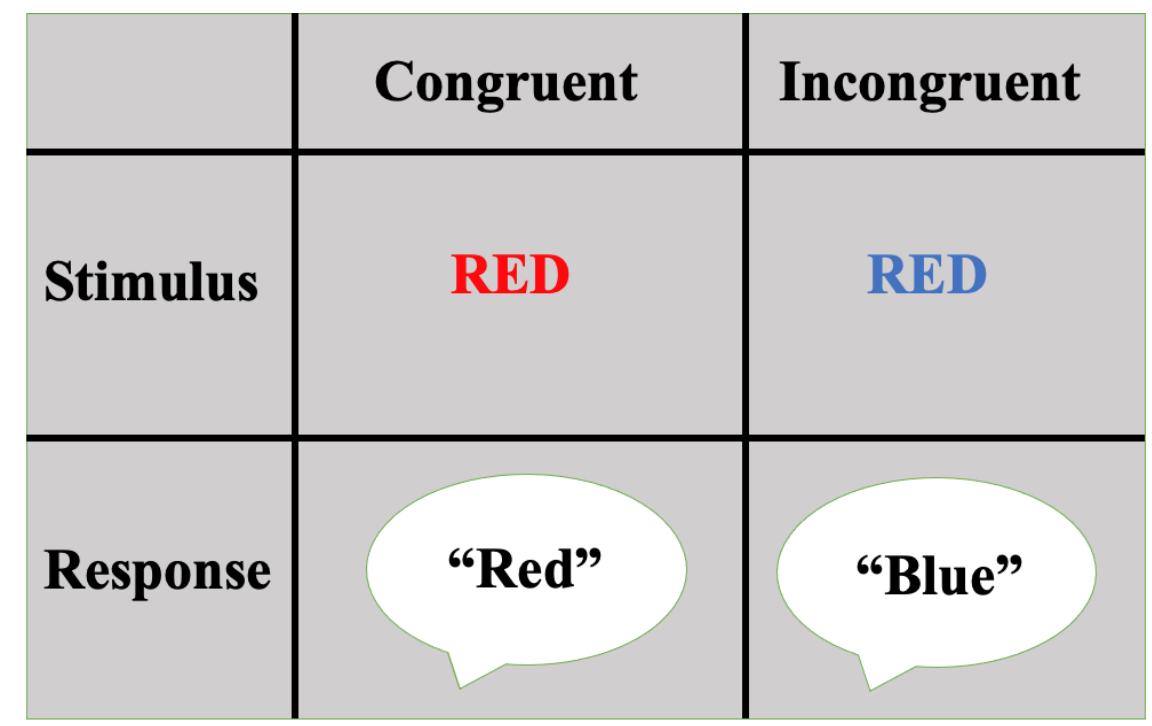

Figure 1. Stroop Task: Participants are to name the colour of the word presented on the screen. Congruent trials are when the colour of the word, and the colour of the word itself, are the same. Incongruent trials are indicated by differing word and font colour.

This task allows us to measure the Stroop effect, which is the difference between incongruent and congruent conditions [9]. Participants should display longer reaction times (RTs) and increased error rates for incongruent than congruent conditions. This task will measure selective attention through behavioural measures (accuracy and RT) and N450 and P3 ERP indices. $\underline{\text { Simon Task }}$

The Simon task evaluates inhibition and spatial reasoning. Participants will be shown either a red or green image, representing the right and left positions respectively [10]. They will be instructed to press a key corresponding to the colour ( $\mathrm{F}$ for green and $\mathrm{J}$ for red) using the left and right index fingers respectively while ignoring the location of the

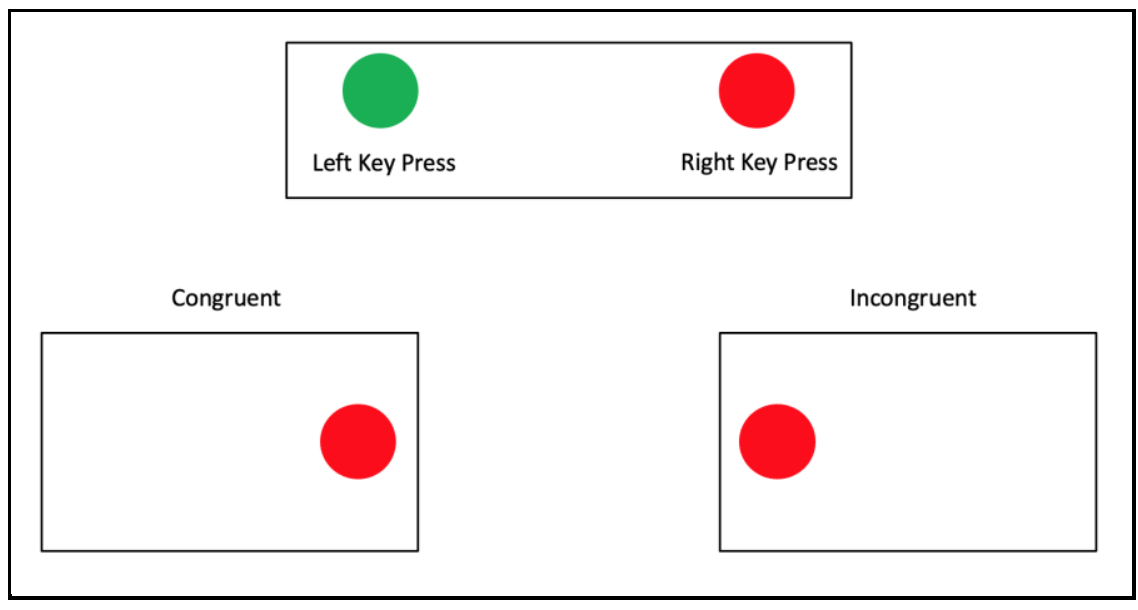

Figure 2. Simon Task: Participants are to press the designated key (left or right key press) based on the colour shown on the screen. A congruent trial consists of stimuli showing up on the side of the screen that coincides with the location of the key. An incongruent trial is when the stimuli appears on the opposite side of the screen with respect to the correct response key.

stimulus whether it is in the left or right hemispace. Congruent trials are when red stimuli are presented on the

This task allows us to examine the Simon effect: differences in RTs or accuracy between incongruent and congruent conditions [11]. RTs tend to be slower and less right side of the screen, whereas incongruent trials consist of stimuli shown on the opposite side of the screen (Figure 2). accurate for incongruent compared to congruent trials. $\mathrm{N} 2 \mathrm{pc}$ and PD ERP components will be used to measure 
UNDERGRADUATE RESEARCH IN NATURAL AND CLINICAL SCIENCE AND TECHNOLOGY (URNCST) JOURNAL Read more URNCST Journal articles and submit your own today at: https://www.urncst.com

attentional selection and suppression of visual distraction [11].

\section{$\underline{\text { Single N-Back Task }}$}

The n-back task involves working memory to maintain rapidly changing information [12]. Two versions will be conducted to test for visual and auditory working memory. Individuals will be presented with a sequence of either visual stimuli (e.g., on-screen images) or auditory stimuli (e.g, spoken monosyllabic words). Participants will be asked to identify the stimulus presented three stimuli prior in the series. Working memory performance will be measured by accuracy and RTs, and the P3 [12].

\section{$\underline{\text { Arithmetic Tasks }}$}

Participants will undergo two arithmetic tasks. The numerical comparison task involves presenting two distinct numbers briefly shown one after the other. Participants will be required to identify the higher number. During the calculation task, participants are presented with one number and one simple multiplication statement. They are to determine whether the number presented, or the product of

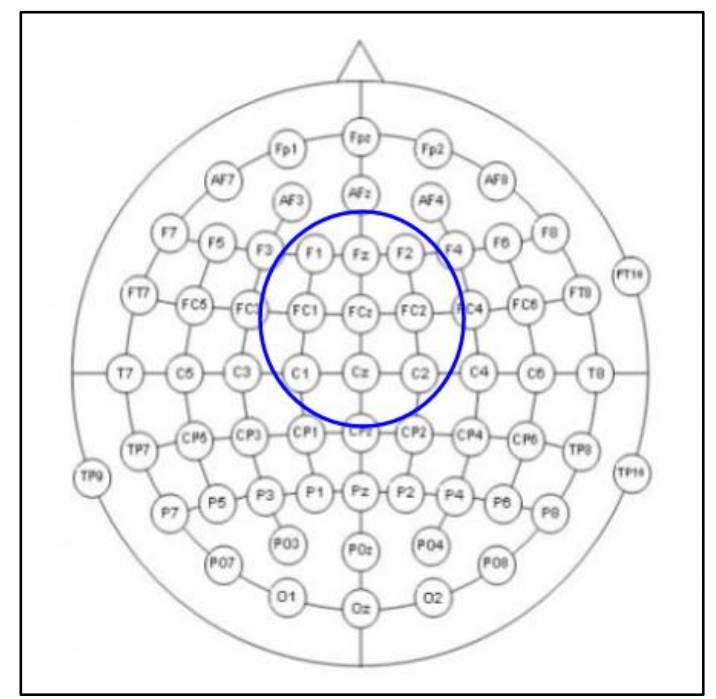

Figure 3a. The mean amplitude will be extracted from a cluster of 9 electrodes surrounding the $\mathrm{FCz}$ electrode to measure the Simon N2pc component in the 64-electrode montage.

For peak latency analysis, the peak of an ERP component is defined as the latency of the local maximum positivity or negativity within a specified time window. At ranges 8-13 $\mathrm{Hz}$ and 4-7 $\mathrm{Hz}$ alpha and theta power will be observed respectively $[14,15]$. Alpha and theta power will be extracted using Fast Fourier transform and differences in power will be examined. the statement is greater. Changes in oscillatory power in alpha and theta frequencies for both tasks will be recorded to measure attention and working memory [13].

\section{Preprocessing}

Behavioural measures (accuracy and RTs) will be averaged for each condition and across participants per group. For EEG measures, the data will be re-referenced to the average reference (i.e. the average of all channels) and filtered between 0.5 to $40 \mathrm{~Hz}$. Upon visual inspection, mean amplitudes for each ERP component of interest will be extracted and averaged over a 200 to $400 \mathrm{~ms}$ time window surrounding the peak of the component. For the Simon N2pc component, the mean amplitude will be extracted from 150-350 ms from a cluster of 9 electrodes surrounding the FCz electrode (Figure 3a). For the PD index from the Simon task, as well as the N450 and P3 indices from the Stroop task, the mean amplitude will be extracted from 250-650 ms from a cluster of 9 electrodes surrounding $\mathrm{CPz}$ (Figure 3b).

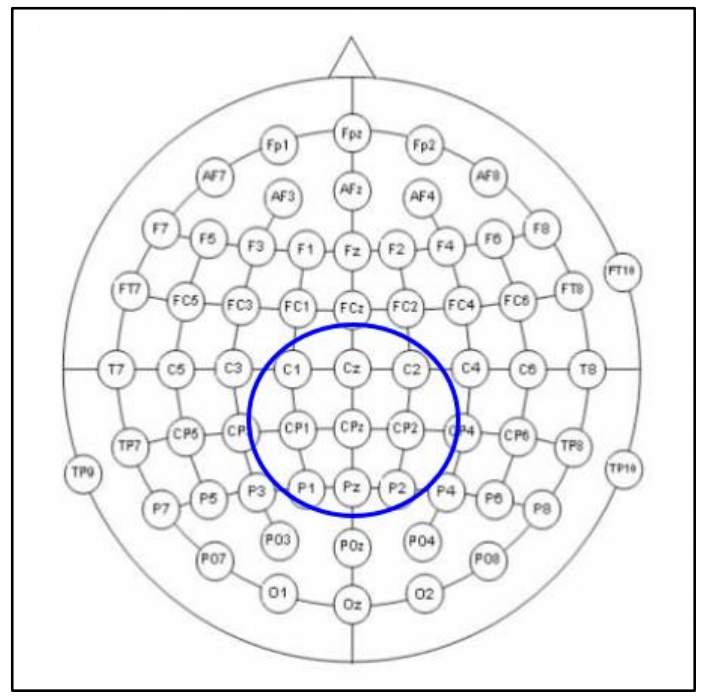

Figure 3a. The mean amplitude will be extracted from a cluster of 9 electrodes surrounding the $\mathrm{FCz}$ electrode to measure the Simon N2pc component in the 64-electrode montage.

\section{Statistical Analyses}

For the Stroop, Simon, n-back and arithmetic tasks, accuracy and RT values will be subjected to a mixed model ANOVA with group (adolescents, younger adults) as a between-subjects factor, and time of day (morning, evening) and condition (incongruent, congruent) as withinsubjects factors. Similarly, mean amplitudes and peak latencies for the N2pc, PD, N450, P3 components will be 
UNDERGRADUATE RESEARCH IN NATURAL AND CLINICAL SCIENCE AND TECHNOLOGY (URNCST) JOURNAL Read more URNCST Journal articles and submit your own today at: https://www.urncst.com

subjected to an ANOVA with the same factors of group, time of day, and condition. Post-hoc t-tests with Sidak correction will be conducted. The pre and post-stimulus power will be compared using cluster-based permutation testing. An alpha value of 0.05 will be used.

\section{Results}

$\underline{\text { Behavioural Measures }}$

For Stroop and Simon tasks, a two-way interaction is anticipated for the TOD and the conditions (incongruent, congruent) in which there will be higher Stroop and Simon effects in the morning than evening for both groups. We may expect larger effect sizes in young adults than in teenagers. Both groups will demonstrate greater accuracy and quicker RTs while performing the n-back and arithmetic tasks during the evening than morning. Additionally, as participants progress through these tasks, we expect a decrease in accuracy over time, as well as slower RTs due to fatigue. Similar to the Stroop and Simon tasks, we also expect greater effect sizes in young adults compared to adolescents in ERP measures.

\section{ERP Mean Amplitudes and Peak Latencies}

Similarly, ERPs will demonstrate a two-way interaction between TOD and task conditions (incongruent and congruent), as determined from differences in amplitudes for the ERP indices of N2pc and PD for the Simon task, and N450 and P3 for the Stroop task (Figure 4).

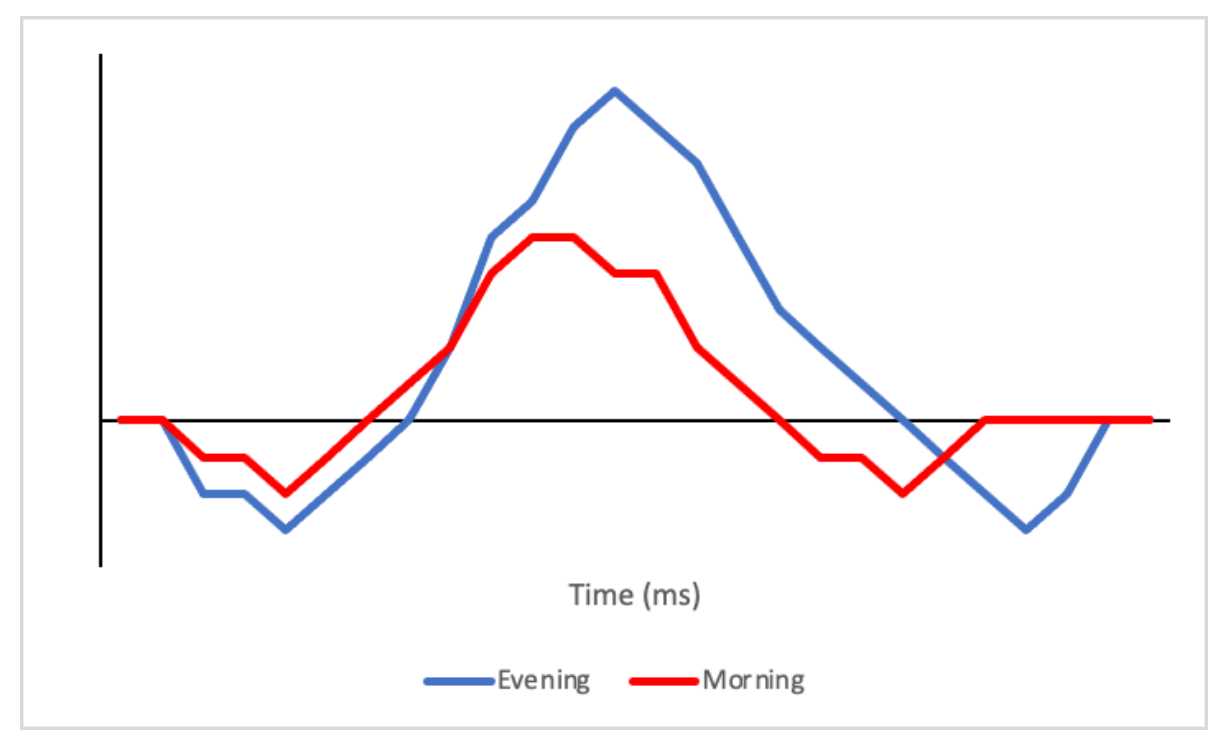

Figure 4. Sample ERP waveform from stimulus onset for the N450 index for the Stroop task. The figure displays higher amplitudes in the evening compared to in the morning.

Consistent with prior EEG research [16,17], we expect greater differences in amplitude for Stroop and Simon effects during the evening than morning in both groups. Regarding the single n-back test, there will be significant differences in the P3 amplitude between morning and evening times, such that the $\mathrm{P} 3$ will be higher in the evening than morning in both groups. For each of the tasks, there will be longer peak latencies for the N2pc, PD, N450, and P3 indices in the evening in all task conditions compared to the morning and across both groups. These latency differences will be associated with RT and accuracy using post-hoc correlation analyses. In the arithmetic tasks, young adults and adolescents will show increased alpha and theta power in the evening compared to the morning [16]. This would be consistent with prior research showing that higher alpha power has been associated with greater levels of attention, and higher theta power has been associated with greater cognitive effort [18].

\section{Discussion}

This research protocol aims to quantify TOD differences in adolescents and younger adults by measuring ERP indices (P3, N2pc, PD, N450) and alpha and theta frequencies. The protocol proposes using both neuroimaging and behavioural measures, as EEG has shown to be sensitive to time of day effects [19]. According to the expected results, adolescents would perform better in the evening compared to the morning which is reflected by their optimal time of day. ERP and behavioural data will demonstrate larger effects due to the time of day in young adults compared to adolescents. This larger effect is due to all individuals in the young adult's group already undergone a shift in their circadian rhythm which makes them more vulnerable to performance changes at different times of day. This is shown through differences in amplitude, RTs, and accuracy across an individual's optimal and non-optimal time of day. In the evening, all individuals are expected to perform with more accuracy, faster RTs, and greater peak latencies in ERP components 
UNDERGRADUATE RESEARCH IN NATURAL AND CLINICAL SCIENCE AND TECHNOLOGY (URNCST) JOURNAL Read more URNCST Journal articles and submit your own today at: https://www.urncst.com

compared to tasks completed in the morning. This is due to higher attentional effort, ability to suppress distractions via the Stroop and Simon task, and working memory via the nback task. For the arithmetic tasks, it is expected that the alpha and theta power will increase in the evening for both populations. This is due to individuals becoming more attentive and using their executive control in the evening compared to the morning [20].

The optimal time of day for individuals is highly dependent on their circadian rhythm, in particular, when tasks involving cognition and effort are being completed. Cognitive ability seems to be improved at their peak arousal time and decreases the further one gets from this peak time. Throughout the developmental stages of childhood, there is a constant improvement regarding the executive function that continues during adolescence. This includes the effortful cognitive control of thought, action, and emotion an individual presents during a given task [19]. Differences in the development of executive function is an important aspect that can be used to predict an individual's overall cognitive function and success in school. In particular, when looking at adolescent years, peak times begin to change from the morning to the evening which is reflected in their chronotypes which results in lower cognitive abilities and decreased attentional effort during the morning compared to the evening hours [19]. Studies have have shown that adolescents are more prone to show lowered executive function when tested at their non-optimal time compared to any other variable including amount of sleep received, demonstrating the importance ones sleep-wake pattern has on their overall functioning [19].

Although research has demonstrated that peak performance is greatly affected by one's circadian rhythm, young adults and adolescents are forced to accommodate to the optimal time of day for older individuals. Though the purpose of education is catered to the younger demographic, the timing of lessons and assessments are not ideal for the learning and performance of adolescents [20]. In Canada, the majority of school days start between 8 and $9 \mathrm{AM}$ and end around 3 to $4 \mathrm{PM}$. As most of this age group functions optimally in the afternoon and evening, this specific timing interrupts and adolescents' and young adults' natural circadian rhythm [2]. This is especially detrimental when looking at performance on tasks requiring a sufficient amount of cognitive effort. In a study done by Randler and Frech, morning-type adolescents who slept for longer periods of time experienced an increase in their academic grades compared to those who got less sleep [20]. This lack of sleep was due to early school start times, which only benefited those who were morning people. Since children usually go through a transition phase from morning to evening chronotypes at around 12-13 years old [19], their learning would greatly benefit with a shift to later school start times. Indeed, several schools in Australia have implemented this late start and have seen increases in academic performance [21].

Clarizio et al. | URNCST Journal (2022): Volume 6, Issue 2 DOI Link: https://doi.org/10.26685/urnest.270
Adolescents are suffering from a lack of sleep due to early school start times [22]. Lack of sleep leads to many consequences such as chronic sleep loss, deteriorating physical and mental health, and decreased academic achievement. Recent studies have shown that the disruption of circadian rhythms in high school and post-secondary students leads to anxiety and mood disorders [20]. In fact, schools that have implemented late start times have seen decreased depressive symptoms from insufficient sleep [23].

A discrepancy between an individual's test score and their actual cognitive ability can have a lasting impact, especially when looking at standardized tests such as the Scholastic Aptitude Test (SAT) [24]. The pressure to do well on these tests paired with taking the assessment at non-optimal times of day can drastically decrease one's score. Tests such as the SATs are used for admissions into higher education and ultimately decide future career paths. It is important that one is able to perform their best while taking these tests as, for many, it defines the rest of their life [24]. In order to maintain validity and fairness to all test-takers, flexibility in test-taking time should be implemented [24]. For this reason, it would be beneficial for the academic future of adolescents and young adults to have later standardized test-taking times, as it would enable fair assessments without consequences of TOD misalignment.

Some limitations in this study can be attributed to the willingness of the participants to complete these tasks at predetermined times. Further, the variability in results due to fatigue, motivation, and overall effort over multiple testtaking sessions may hinder the validity of the EEG measures. To account for these limitations, substantial monetary compensation can be awarded to participants.

\section{Conclusions}

Overall, the alignment of tasks with one's circadian rhythm is imperative to academic performance, cognitive capabilities, and mental health, particularly in adolescents and young adults. Any disruption in one's sleep-wake cycle will have severe negative effects on one's learning and testtaking abilities. It is important to consider this when looking at the lifestyles of adolescents and young adults, as their optimal time of day is generally in the afternoon and evening. The implications of this study are far-reaching in all levels of society including long-term education, employment, and overall quality of life.

\section{List of Abbreviations Used \\ TOD: time of day \\ EEG: electroencephalography \\ ERP: event-related potentials \\ $\mathrm{RT}$ : reaction time \\ SAT: scholastic aptitude test}


UNDERGRADUATE RESEARCH IN NATURAL AND CLINICAL SCIENCE AND TECHNOLOGY (URNCST) JOURNAL Read more URNCST Journal articles and submit your own today at: https://www.urncst.com

\section{Conflicts of Interest}

The authors declare that they have no conflicts of interest.

\section{Ethics Approval and/or Participant Consent}

The participants involved in this study will need to give consent to be used in this research. Consent should be obtained from individuals over the age of 18 and from both the individuals and their legal guardians if they were under the age of 18. A detailed procedure, the risks involved, and the ethical codes and regulations will be supplied to all participants, and consent will be contained in a written form. When informed consent is collected, there will be minimized influence and the participant will be given sufficient time to consider participation.

\section{Authors' Contributions}

GC: made substantial contributions to the design of the study, analyzed the anticipated results as well as interpreting the data, revised the manuscript critically, and gave final approval of the version to be published.

PG: made substantial contributions to the design of the study, analyzed the anticipated results as well as interpreting the data, revised the manuscript critically, and gave final approval of the version to be published.

\section{Acknowledgments}

Thank you to Ricky Chow for overseeing this study and helping with the editing process, as well as generally supporting the research conducted. Figures 1 to 3 were created using Microsoft Powerpoint software, and Figure 4 was created using Microsoft Excel.

\section{Funding}

This study was not funded.

\section{References}

[1] Vitaterna M, Takahashi J, Turek F. Overview of circadian rhythms. Alcohol Research \& Health. 2001;25(2):85-93. Available from: https://pubmed .ncbi.nlm.nih.gov/11584554/

[2] Duffy J, Zitting K, Chinoy E. Aging and circadian rhythms. Sleep Medicine Clinics. 2015;10(4):423-434. https://doi.org/10.1016/j.jsmc.2015.08.002

[3] Smit A, Michalik M, Livingstone A, Mistlberger R, McDonald J. Circadian misalignment impairs ability to suppress visual distractions. Psychophysiology. 2019;57(2). https://doi.org/10.1111/psyp.13485

[4] Huang B, Zhao X, Li H, Yang W, Cui S, Gao Y et al. Arithmetic skill may refine the performance of individuals with high math anxiety, especially in the calculation task: An ERP STUDY. Scientific Reports. 2019;9(1). https://doi.org/10.1038/s41598-019-49627-7

[5] Avizhgan M, Liaghatdar M, Ashoorion V. Compare the educational achievement of medical students with different circadian rhythms in difficult courses of basic sciences. Advanced Biomedical Research. 2016;5(1):58. https://doi.org/10.4103/2277-9175.178806

Clarizio et al. | URNCST Journal (2022): Volume 6, Issue 2 DOI Link: https://doi.org/10.26685/urncst.270
[6] Schmidt C, Peigneux P, Cajochen C. Age-related changes in sleep and circadian rhythms: Impact on cognitive performance and underlying neuroanatomical networks. Frontiers in Neurology.

2012;3:118. https://doi.org/10.3389/fneur.2012.00118

[7] Zamanian Z, Dehghani M, Hashemi H. Outline of changes in cortisol and melatonin circadian rhythms in the security guards of Shiraz University of Medical Sciences. International Journal of Preventative Medicine. 2013;4(7):825-830. Available from: https://www.ncbi.nlm.nih.gov/pmc/articles/PMC37752 23/

[8] Alhajj M, Farhana A. Enzyme Linked Immunosorbent Assay. StatPearls Publishing. 2021 Feb 6. Available from: https://pubmed.ncbi.nlm.nih.gov/32310382/

[9] Scarpina F, Tagini S. The Stroop color and word test. Frontiers in Psychology. 2017;8. https://doi.org/ 10.3389/fpsyg.2017.00557

[10] Mahani M, Bausenhart K, Ahmadabadi M, Ulrich R. Multimodal Simon effect: A multimodal extension of the diffusion model for conflict tasks. Frontiers in Human Neuroscience. 2019;12. https://doi.org/ 10.3389/fnhum.2018.00507

[11] Wascher E, Wolber M. Attentional and intentional cueing in a Simon task: An EEG-based approach. Psychological Research. 2004;68(1):18-30. https://doi.org/10.1007/s00426-002-0128-Z

[12] Gajewski P, Hanisch E, Falkenstein M, Thönes S, Wascher E. what does the n-back task measure as we get older? Relations between working-memory measures and other cognitive functions across the lifespan. Frontiers in Psychology. 2018;9. https://doi.org/10.3389/fpsyg.2018.02208

[13] Michelmann S, Bowman H, Hanslmayr S. The temporal signature of memories: Identification of a general mechanism for dynamic memory replay in humans. PLOS Biology. 2016;14(8):e1002528. https://doi.org/10.1371/journal.pbio.1002528

[14] Griffiths B, Parish G, Roux F, Michelmann S, van der Plas M, Kolibius L et al. Directional coupling of slow and fast hippocampal gamma with neocortical alpha/beta oscillations in human episodic memory. Proceedings of the National Academy of Sciences. 2019;116(43):21834-21842. https://doi.org/10.1073/ pnas. 1914180116

[15] Atchley R, Klee D, Oken B. EEG frequency changes prior to making errors in an easy Stroop task. Frontiers in Human Neuroscience. 2017;11. https://doi.org/ 10.3389/fnhum.2017.00521

[16] Klimesch W. Alpha-band oscillations, attention, and controlled access to stored information. Trends in Cognitive Sciences. 2012;16(12):606-617. https://doi.org/10.1016/j.tics.2012.10.007 
UNDERGRADUATE RESEARCH IN NATURAL AND CLINICAL SCIENCE AND TECHNOLOGY (URNCST) JOURNAL

Read more URNCST Journal articles and submit your own today at: https://www.urncst.com

[17] Casarotto S, Romero Lauro L, Bellina V, Casali A, Rosanova M, Pigorini A et al. EEG responses to TMS are sensitive to changes in the perturbation parameters and repeatable over time. Public Library of Science ONE. 2010;5(4):e10281.

https://doi.org/10.1371/journal.pone.0010281

[18] Rodriguez-Larios J, Faber P, Achermann P, Tei S, Alaerts K. From thoughtless awareness to effortful cognition: Alpha-theta cross-frequency dynamics in experienced meditators during meditation, rest and arithmetic. Scientific Reports. 2020;10(1).

https://doi.org/10.1038/s41598-020-62392-2

[19] Hahn C, Cowell J, Wiprzycka U, Goldstein D, Ralph M, Hasher L et al. Circadian rhythms in executive function during the transition to adolescence: The effect of synchrony between chronotype and time of day. Developmental Science. 2012;15(3):408-416. https://doi.org/10.1111/j.1467-7687.2012.01137.x

[20] Randler C, Frech D. Young people's time-of-day preferences affect their school performance. Journal of Youth Studies. 2009;12(6):653-667. https://doi.org/ $10.1080 / 13676260902902697$
[21] Sievertsen H, Gino F, Piovesan M. Cognitive fatigue influences students' performance on standardized tests. Proceedings of the National Academy of Sciences. 2016;113(10):2621-2624. https://doi.org/10.1073/pnas .1516947113

[22] Owens J, Belon K, Moss P. Impact of delaying school start time on adolescent sleep, mood, and behavior. Archives of Pediatrics \& Adolescent Medicine. 2010; 164(7). https://doi.org/10.1001/archpediatrics.2010.96

[23] Au R, Carskadon M, Millman R, Wolfson A, Braverman P, Breuner C et al. School start times for adolescents. Pediatrics. 2014;134(3):642-649. https://doi.org/10.1542/peds.2014-1697

[24] Amrein A, Berliner D. The impact of high-stakes tests on student academic performance: An analysis of NAEP results in states with high-stakes tests and ACT, SAT, and AP test results in states with high school graduation exams. Arizona State University Education Policy Studies Laboratory. 2002. Available from: https://nepc.colorado.edu/sites/default/files/EPSL0211-126-EPRU.pdf

\section{Article Information}

Managing Editor: Jeremy Y. Ng

Peer Reviewers: Ricky Chow, Bi-ru Amy Yeung

Article Dates: Received Mar 10 21; Accepted Oct 08 21; Published Feb 2522

\section{Citation}

Please cite this article as follows:

Clarizio G, Gill P. The effects of circadian rhythm in adolescents on optimal performance in cognitive tasks. URNCST

Journal. 2022 Feb 25: 6(2). https://urncst.com/index.php/urncst/article/view/270

DOI Link: https://doi.org/10.26685/urncst.270

\section{Copyright}

(C) Giulia Clarizio, Priyanka Gill. (2022). Published first in the Undergraduate Research in Natural and Clinical Science and Technology (URNCST) Journal. This is an open access article distributed under the terms of the Creative Commons Attribution License (https://creativecommons.org/licenses/by/4.0/), which permits unrestricted use, distribution, and reproduction in any medium, provided the original work, first published in the Undergraduate Research in Natural and Clinical Science and Technology (URNCST) Journal, is properly cited. The complete bibliographic information, a link to the original publication on http://www.urncst.com, as well as this copyright and license information must be included.
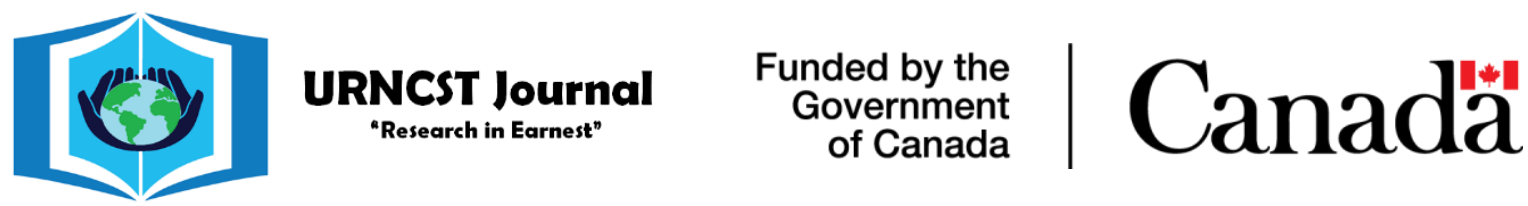

Do you research in earnest? Submit your next undergraduate research article to the URNCST Journal!

| Open Access | Peer-Reviewed | Rapid Turnaround Time | International |

| Broad and Multidisciplinary | Indexed | Innovative | Social Media Promoted |

Pre-submission inquiries? Send us an email at info@ urncst.com | Facebook, Twitter and LinkedIn: @URNCST

Submit YOUR manuscript today at https://www.urncst.com! 